> differences between fields. "Take a group of smart biologists and put them in a room of smart computer scientists and they will talk two different languages to each other, and have different mindsets," says Daphne Koller, chief computing officer at Calico - a biotechnology company in San Francisco, California, that is backed by Google's parent, Alphabet.

Scientists also had to identify which types of study could be conducted using networks that must be trained with huge sets of images before they can start making predictions. When Google wanted to use deep learning to find mutations in genomes, its scientists had to convert strands of DNA letters into images that computers could recognize. Then they trained their network on DNA snippets that had been aligned with a reference genome, and whose mutations were known. The end result was DeepVariant, a tool released in December that can find small variations in DNA sequences. In tests, DeepVariant performed at least as well as conventional tools.

Cell biologists at the Allen Institute for Cell Science in Seattle, Washington, are using convolutional neural networks to convert flat, grey images of cells captured with light microscopes into 3D images in which some of a cell's organelles are labelled in colour. The approach eliminates the need to stain cells - a process that requires more time and a sophisticated lab, and can damage the cell. Last month, the group published details of an advanced technique that can predict the shape and location of even more cell parts using just a few pieces of data - such as the cell's outline (G. R. Johnson et al. Preprint at bioRxiv http://doi.org/chwv; 2017).

"What you're seeing now is an unprecedented shift in how well machine learning can accomplish biological tasks that have to do with imaging," says Anne Carpenter, director of the Imaging Platform at the Broad Institute of MIT and Harvard in Cambridge, Massachusetts. In 2015 , her interdisciplinary team began to process cell images using convolutional neural networks; now, Carpenter says, the networks process about $15 \%$ of image data at her centre. She predicts that the approach will become the centre's main mode of processing in a few years.

Others are most excited by the idea that analysing images with convolutional neural networks could inadvertently reveal subtle biological phenomena, prompting biologists to ask questions they might not have considered before. "The most interesting phrase in science isn't 'Eureka!', but 'That's weird - what's going on?"” Nelson says.

Such serendipitous discoveries could help to advance disease research, says Rick Horwitz, the Allen Institute's executive director. If deep learning can reveal subtle markers of cancer in an individual cell, he says, it could help to improve how researchers classify tumour progression. That could in turn trigger new hypotheses about how cancer spreads.

Other machine-learning connoisseurs in biology have set their sights on new frontiers, now that convolutional neural networks are taking flight for image processing. "Imaging is important, but so is chemistry and molecular data," says Alex Wolf, a computational biologist at the German Research Center for Environmental Health in Neuherberg. Wolf hopes to tweak neural networks so that they can analyse gene expression. "I think there will be a very big breakthrough in the next few years," he says, "that allows biologists to apply neural networks much more broadly." -

\title{
Facebook billionaire pours funds into high-risk research
}

\section{Silicon Valley philanthropy project revives some grants rejected by US government.}

\section{BY EWEN CALLAWAY}

A fter his plan to test a cancer vaccine for middle-aged pet dogs was rejected by the US National Institutes of Health $(\mathrm{NIH})$, inventor and biochemist Stephen Johnston sought funding outside the mainstream system. On 20 December, the Open Philanthropy Project, a grant-giving organization that is largely funded by Facebook cofounder Dustin Moskovitz and his wife, Cari Tuna, announced that Johnston will receive US\$6.4 million to test the vaccine he developed. His team at Arizona State University in Tempe is now poised to enrol its first pooches in a clinical trial.

The science-funding efforts of the Open Philanthropy Project, or Open Phil, have so far flown under the radar compared with those of other Silicon Valley funders. But that is likely to change. The organization, which was launched in 2011 but rebranded under its current name in 2014, has significantly boosted its spending to $\$ 200$ million this year, of which around $\$ 40$ million went to scientific research. And Chris Somerville, a biochemist and a scientific adviser to the organization, says that Open Phil's total spending will rise several times over the coming years.
Moskovitz, whose estimated net worth is more than $\$ 14$ billion, and Tuna have said that they plan to give away most of their fortune during their lifetimes. It is likely that,

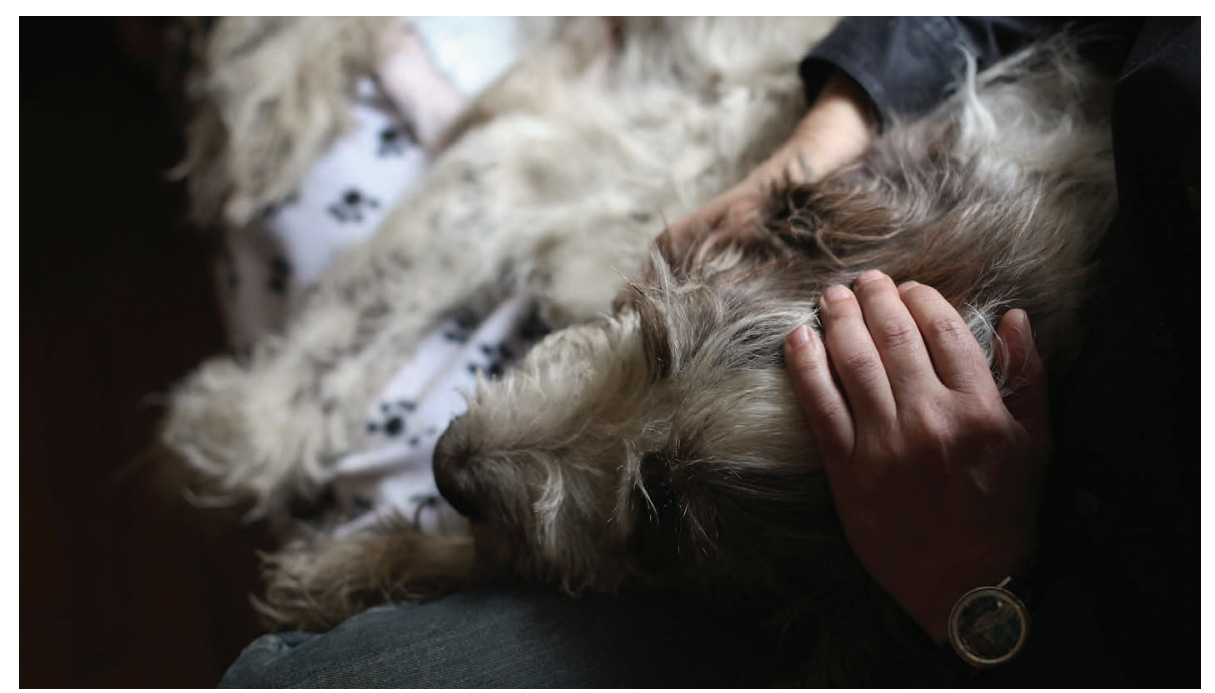

Dogs with cancer are about to be enrolled in a clinical trial of a vaccine for the disease. 
in terms of impact on research, Open Phil will soon rival better-known philanthropy vehicles, such as the Chan Zuckerberg Initiative in Palo Alto, California, which among other efforts awarded $\$ 50$ million in life-sciences grants in 2017 to create a biohub in the San Francisco Bay Area.

Open Phil, based in San Francisco, acknowledges the high odds of failure of the basic research it funds and, for a private funder, publishes brutally honest assessments of its projects. These range from developing lab-made meat alternatives to work on a controversial genetic-engineering technology called gene drive. For its latest funding round, Open Phil asked scientists whose grant applications had been rejected by an NIH competition for risky research to dust off their proposals. Some 120 researchers resubmitted their requests, and it awarded $\$ 10.8$ million in total to four teams.

"My hope is Open Philanthropy can make the world safe for serendipity again," says Ed Boyden, a neuroscientist at the Massachusetts Institute of Technology in Cambridge, who won $\$ 3$ million from the project in 2016 . He is working to develop a technology that swells tissue to make it easier to examine under a microscope.

\section{TAKING A PUNT}

Gregory Timp, a biophysicist at the University of Notre Dame in South Bend, Indiana, who has won $\$ 2$ million from Open Phil to develop a technology to sequence proteins, says that the evaluation process involved rebutting each of the NIH's critiques of his proposal, as well as several rounds of interviews with scientist advisers. "They have scientific rigour couched in California casual. Everything is informal, but they ask these piercing questions," he says.

Katherina Rosqueta, founding executive director of the Center for High Impact Philanthropy at the University of Pennsylvania in Philadelphia, says that the project's efforts to share its extensive research and justify its giving makes it stand out among private funders. "They have a highly analytical view. They have an appetite and skill in conducting research and sourcing information, and they're willing to do that in a public and transparent way."

Many philanthropists shy away from basic science because the pay-offs tend to be long term and the risks high, says Marc Kastner, president of the Science Philanthropy Alliance in Palo Alto, a coalition of foundations that advocates for private funding of basic science. But the Silicon Valley entrepreneurs who bankroll organizations such as the Open Philanthropy Project and the Chan Zuckerberg Initiative are used to long odds, says Kastner. "The risk-taking is not an issue for them. They don't want to be supporting a sure thing." -

\section{BIOSECURITY}

Ban on pathogen
studies lifted

\section{United States allows work to make viruses more dangerous.}

\section{BY SARA REARDON}

$\mathrm{T}$ The US government has lifted its controversial ban on funding experiments that make certain pathogens more deadly or transmissible. On 19 December, the National Institutes of Health (NIH) announced that scientists can once again use federal money to conduct 'gain-of-function' research on pathogens such as influenza viruses. But the agency also said that researchers' grant applications will undergo greater scrutiny than in the past.

The goal is to standardize "a rigorous process that we really want to be sure we're doing right", says NIH director Francis Collins.

The NIH announcement ends a moratorium on gain-of-function research that began in October 2014. Back then, some researchers argued that the agency's ban - which singled out research on the viruses that cause flu, severe acute respiratory syndrome and Middle East respiratory syndrome (MERS) - was too broad. The 21 projects halted by the policy included studies of seasonal flu and efforts to develop vaccines. The NIH eventually allowed ten of these studies to proceed, but three projects using the MERS virus and eight dealing with flu remained ineligible for US government grants - until now.

While the ban was in effect, the NIH and other government agencies examined the costs and benefits of allowing such research. In 2016, the National Science Advisory Board for Biosecurity - an independent panel that advises the NIH's parent agency, the US Department of

\section{Gain-of- function studies "risked creating an accidental pandemic".}

Health and Human Services (HHS) - concluded that very few government-funded gainof-function experiments posed a significant threat to public health.

The new policy outlines a framework that the HHS will use to assess proposed research that would create pathogens with pandemic potential. Such work might involve modifying a virus to infect more species, or recreating a pathogen that has been eradicated in the wild, such as smallpox. There are some exceptions, however: vaccine development and epidemiological surveillance do not automatically trigger the HHS review.

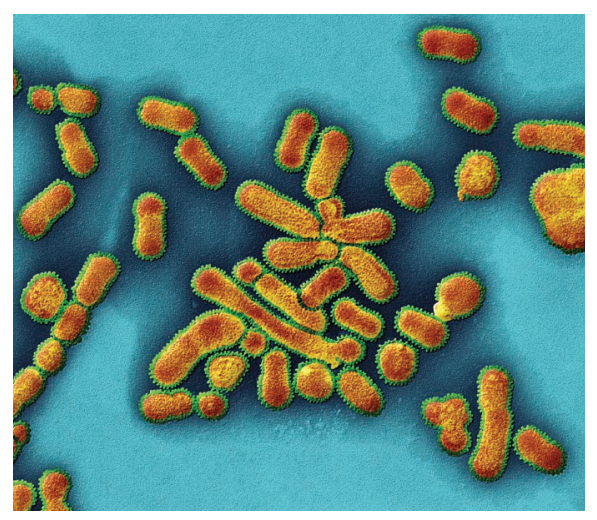

Influenza viruses can be modified in the lab.

The plan includes a list of suggested factors for the HHS to consider, including an assessment of a project's risks and benefits, and a determination of whether the investigator and institution are capable of conducting the work safely. It also says that an experiment should proceed only if there is no safer alternative method of achieving the same results.

At the end of the assessment process, the HHS can recommend that the work go ahead, ask the researchers to modify their plan or suggest that the NIH refuse funding. The NIH will also judge the proposal's scientific merit before deciding whether to award grant funding.

Scientists have long debated the merits of gain-of-function research and the new decision could reopen that discussion.

Yoshihiro Kawaoka, a virologist at the University of Wisconsin-Madison, whose work was affected by the moratorium, says the new framework is "an important accomplishment". Kawaoka, who studies how molecular changes in the avian flu virus could make it easier for birds to pass the infection to humans, now plans to apply for federal funding to experiment with live versions of the virus.

But Marc Lipsitch, an epidemiologist at the Harvard T.H. Chan School of Public Health in Boston, Massachusetts, says that gain-offunction studies "have done almost nothing to improve our preparedness for pandemics - yet they risked creating an accidental pandemic".

Lipsitch argues that such experiments should not happen at all. But if the government is going to fund them, he says, it is good that there will be an extra level of review. 